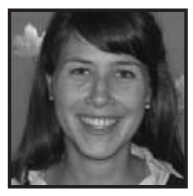

\title{
Making the Invisible Process Visible: A Kinesthetic Approach to Explicit Reading Comprehension Strategy Instruction in Early Primary Grades
}

\author{
Sarah Kingsley, Lower Canada College
}

\section{ABSTRACT}

Reading instruction in early primary grades tends to focus on segmenting words into sounds and there is little emphasis on explicitly teaching reading comprehension strategies. Through a kinesthetic approach, l attempted to make the invisible process of applying reading comprehension strategies visible. Students used a remote, similar to that of a TV, to play and pause their reading process. This enabled them to effectively use meaning-making strategies which took shape through signaling. Students would physically motion to themselves various signs which indicated the four reading comprehension strategies modeled in my think alouds (visualization, questioning, making predictions and making connections). The outcome was a highly motivated group of grade one students who could apply reading comprehension strategies and engage in discourse that reflected a higher level of understanding.

\section{Introduction}

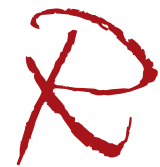

eading is the foundation for a successful education and the means to academic growth. As educators, we have the responsibility to instruct our students how to read and how to derive meaning from the written word. In the early primary grades, instruction emphasizes the development of phonemic awareness, word recognition, and reading fluency (Block, Parris, \& Cinnamon, 2008). Although these components are required to initiate reading processes, they are only one facet of a complex network of strategies that work in conjunction with one 
another to foster reading comprehension (Diehl, 2005). Block et al. (2008) attest that contemporary research suggests, “...comprehension instruction should become an essential feature in primary-grade literacy programs" (p. 460). Specifically in early childhood education, we are limiting our students' ability to read by focusing entirely on phonological processes and neglecting to teach meaning-making strategies. It is imperative as educators that we re-evaluate our teaching methods to ensure we are providing explicit instruction on reading comprehension strategies at the early primary grades. Through a kinesthetic approach, young students can grasp the abstract notion of reading comprehension strategies. By engaging their bodies in the process, making predictions, visualizing and questioning become tangible concepts that inevitably improve a child's interaction and understanding of a text.

\section{My Motivation}

I began my teaching career only a year ago and was both excited and overwhelmed with my role as a grade one Language Arts teacher. I knew the importance of reading instruction and made sure it was at the forefront of my curriculum. However, like so many early primary educators, I focused on teaching students how to segment words into phonemes in order to decode effectively. As novice readers, I did not think my students had the ability to go beyond the phonological level to think and interact with a text. My students inherited this misconception of reading and began to value and direct all of their attention towards decoding. Their understanding of what constituted "reading" was limited to reading words and not making meaning. Reading comprehension was an entirely different facet from reading. In fact, reading and understanding were established as two separate entities. The shift in my perspective occurred this year as our school began a professional development initiative to encourage interdisciplinary discourse and reflective practice. I was partnered with the head of our resource department, Judy Shenker, who revolutionized my conception of reading and reading instruction. It was Judy that challenged my definition of reading by introducing me to Dolores Durkin who spearheaded the notion of reading comprehension strategy instruction with her findings from the late 1970s. Durkin observed that less than one percent of teaching time was used for explicit reading comprehension instruction (Durkin, 1979). Moreover, she discovered that teachers spent most of their teaching time assessing comprehension through questioning, but rarely taught students strategies they could apply to monitor their understanding and attain the answers to such questions. These findings brought my attention to my own reading instruction. I, in fact, was following this very trend by 
asking students questions on their reading to determine their level of comprehension without ever providing explicit instruction on how to monitor their understanding of the text.

\section{Reforming My Definition and Understanding of Reading}

Before I could reform my instructional methods, I had to first redefine reading and the reading process. Previously, I had understood reading and reading comprehension as two distinct practices. As stated by Pinnell (2003), "People often speak of reading and comprehending as two different (although connected) processes ( $p$. 16)." In my own teaching, I would instruct students the fundamental process of breaking words apart into their individual sounds. I would explore word families and poetry to help my students discover the rhythm of language through repetitive reading. I would assess oral reading using running records and leveled books. Reading comprehension was evaluated as I questioned students during collective and individual reading. It was the textbook formula that is so often seen in an early primary setting. However, Pinnell helped me redefine "reading" by simply stating that "reading is comprehending" (p. 16). Once reading came to imply comprehension, my instruction and perspective shifted. I continued to teach the basic principles of decoding words, but began to incorporate reading comprehension strategy instruction. Because reading comprehension strategies are both complex and abstract in nature, they require explicit and effective instruction. Reading comprehension strategies demand a deliberate thought process and involve visualizing, predicting, questioning and making connections (Dewitz, Jones, \& Leahy, 2009).

\section{Strategies and Metacognition}

Once I had established that I was going to move my reading instruction beyond the phonemic level, I chose a select group of strategies I was going to use. I focused on a set of monitoring signals that Judy had described as being effective in her own teaching: visualizing, re-reading for understanding, thinking about the character and story, questioning, and making text-to-self and text-to-text connections. I wanted the students to not only understand the strategies, but also know how and when to use them. Readers need to self-monitor their process to effectively 
apply reading comprehension strategies. Gentilucci and McKeown (2007) reiterate that, "Reading is a covert process actively controlled by readers to create meaning from text, and the practice of readers 'thinking about their thinking' while engaged in the reading process is known as metacognition." I came to understand the importance of students developing their metacognition, thinking about their thinking, in order to effectively regulate their reading comprehension independently. I also internalized the value of developing metacognitive awareness in readers as I thought of my personal experience. In my youth, I would read an assigned text and drift off to thinking about clothes, boys, food, etcetera. Within seconds, my thoughts were elsewhere and yet I continued to read. I understood all of the words and their meaning, but I was not thinking about the text. I did not have metacognition and therefore lacked the tools needed to signal that my reading comprehension had shut down. Holly Diehl (2005) defines reading as a "highly metacognitive activity where the reader not only thinks about the material being read, but also monitors that thinking" (p.58). I wanted to help my students make meaning of the text and also develop their metacognition. Yet the idea of metacognition, and monitoring and applying reading comprehension strategies, is a complex process. How could I teach such abstract concepts to my grade one students? Where would I begin?

\section{Process}

Although I was somewhat anxious my students were too young to understand such convoluted ideas, I proceeded to introduce comprehension monitoring strategies. I worried that my weaker readers, who were not yet fluently decoding, would not be ready for strategy instruction and would feel overwhelmed and unsuccessful. In an attempt to make these abstract concepts tangible, I decided that my students needed some sort of a manipulative. Judy told me about Lori Jamison Rog's analogy that reading is like using a remote control. Lori Jamison Rog is an experienced educator who served on the International Reading Association Board of Directors from 1999-2002 and is currently an educational consultant. She has published a number of articles as well as books including Marvelous Minilessons for Teaching Beginning Writing, K-3 (2007) and Early Literacy Instruction in Kindergarten (2001). Based on her idea, I decided to create remote controls for each student with the key buttons (play, stop, pause, rewind and fast-forward). Students were given a token which they would place on the function that they were on. The initial purpose of the remote controls was to teach re-reading when the child misunderstood or misread a word or an idea. If the student's token was on play, they were reading and 
actively engaged in the story. If they moved the token to pause, the student was having trouble understanding a word or an idea. When they moved to rewind, they were re-reading to try to make meaning or double-check what they have already read. If the token was placed on fast-forward, it meant they were skipping that word or idea to move on and try to make sense of it within the full context of the sentence. This initial introduction and use of the remote controls was very successful. I began by modeling the process throughout several lessons. Then students would give me directives as I encountered difficulty reading a word or an idea. Finally, students used the remotes autonomously and understood how and when to manipulate their token. I would circulate throughout the classroom as they engaged in independent reading. They enjoyed modeling their ability to move from play to pause to rewind. The process was a primary step in making my students more aware of their level of comprehension.

Once I felt my students were ready to use the remote control as a multi-purposed tool, I began modeling explicit reading comprehension strategies through think alouds. I turned to Dr. Roger Farr's (2008) model of Think Alongs and gradual responsibility release available on his Web site to initiate this process. Dr. Farr is renowned in the field of education for his many contributions to reading instruction and assessment. He was previously president of the International Reading Association and is currently Director of the Center for Innovation and Assessment at Indiana University. He, along with several colleagues, developed a program that used, "writing as an indicator of how well the reading was understood" and authentically measured their level of success (Farr et al., 1990). On his Web site, Dr. Farr (2008) outlines a seven-day Think Along process that progressively transfers the interactive thought process of good readers from the teacher to the students.

Following Dr. Farr's suggestion, before reading my first Think Along, I identified my intention to have the students observe the strategies I used to help me understand the text. As a class, they were asked to write a list after the story. In this initial step, I wanted my students to see that I could use the remote control for comprehension strategies other than re-reading. I read the story, often moving my token to pause to share a thought. I made connections to other stories and my own life, I modeled visualization, I asked questions and I re-read words and sentences I did not understand. Students were able to tell me the strategies I used and as I wrote them down on the chart, I established our common vocabulary. Once we had compiled our list, I repeated the activity over several days and students determined which strategies I used from the list. They very quickly became familiar with the strategies and what they entailed. Dr. Farr suggests that in the next step, one student prepares a 
Think Along and presents it to the class. I decided that, in order to incorporate more students, I would ask a few to raise their hands and share a thought when I pressed pause. This was an effective way to engage more students in thinking aloud.

When all the students had a strong understanding of the strategies, I proceeded by having them use their individual remotes during independent reading. At first, I circulated to hear their predictions, questions, and connections. They would place their token on pause, raise their hand and then communicate their strategy with me. However, I soon realized that most students would wait to share their thoughts before continuing to read. Because the process was disjointed, their reading inherited this form. I wanted to find a way for my students to signal to me when they made a connection or thought of a question. Dr. Farr (2008) suggests the use of coloured hats to symbolize visualization, making predictions and connections. I think this could be an effective strategy; however I wanted to follow the Comprehension Process Motion Strategy (CPM) model. The CPM model has students use a variety of signals to indicate when they are making predictions, inferring and clarifying (Block et al., 2008). "CPM lessons are designed so that children can internalize comprehension processes, not through repetition or drills but through dual-coded learning inputs so they can develop a true metacognitive understanding of the processes that their brains initiate to obtain meaning" (Block et al., 2008, p. 461). Based on the CPM, I came up with alternate signals that my students could use to indicate to me when they had a question, made a prediction or made a connection. If the students thought of a question, they simply tapped their index finger on their head (to suggest they were thinking). If they made a connection, they would point their thumb at themselves. If they made a prediction, they would flash their hand from a fist position to opening their five fingers up. These were very simple movements but allowed the students to motion to me when they had used a strategy. It also facilitated their reading as they could signal to me and then continue reading. In turn, I could acknowledge their success without having to be in several places at once.

The kinesthetic involvement of students was the most successful facet of this process. It provided the children with a venue to communicate their level of engagement and understanding to themselves and each other. As I read to the whole class, students would signal when they would generate a question, prediction, visualization, or establish a connection. I would pause and give individuals the opportunity to share their questions and connections. Interestingly enough, the dialogue would trigger realizations in other students and they too would begin motioning a reading strategy. Occasionally I would open up the forum for discussion and most often the conversation would be directed and sustained by my students. On an independent 
level, my readers would maintain their focus on the text as they discreetly signaled which reading comprehension strategy they employed.I would circulate and observe their application of reading strategies by listening to their explanation of the signal.

\section{Findings}

This has been an explorative process that continued to evolve with my work for this article. Being a novice teacher I was somewhat hesitant to teach my students such abstract concepts involved with reading comprehension. Once I overcame my own fear and began with the Remote Controls, I realized that the students easily understood their purpose. I only decided to integrate the actions when I discovered the article based on the CPM model. Had I not been researching for this article, my Remote Control Reading would have stopped short, simply teaching students how to re-read. This only re-affirms the need for continuous professional development and research in our field.

There were several factors that hindered the potential of this project. First of all, the idea only evolved from a conversation that I had after the December break. I began the process later in the year and had very little time to develop it. Did my students gain an understanding of reading comprehension strategies? Will these strategies stay with them going into grade two? How will I integrate formal assessment into the process? I am not sure of the answers. It is still very new for the students; therefore, I will only see the long-term benefits or shortcomings of this initiative once the students have had more time to explore this process.

It did, however, give my students a bank of strategies and the vocabulary to discuss reading comprehension. For instance, my students were able to define and describe visualization, making connections and predictions and questioning. One boy signaled the visualizing sign to me as he was reading and said, "Here it always says I'll be there in a minute and don't touch anything and don't move. And I could just visualize Annie sitting there, not moving, not touching anything, just waiting there for Nate the Great to come." Reading comprehension strategies are now wholly integrated into our everyday reading, be it at a whole-class or independent level. My students now use language that I never thought seven-year olds could apply and understand. Another student described how he was thinking about the character, "If like you want to ask the character a question, like if he was actually real and you wanted to ask him 'Why are you looking at that boat?'" They continue to surpass my 
expectations as readers and students who are aware of their own thinking. While reading as a class, we engage in discussions that the students initiate and that stem from their ability to make connections, predictions and ask questions. Furthermore, these comprehension strategies extend into their reading responses. They have developed a skill set that they can use in reading, writing and discussions.

\section{Conclusion}

In so many early elementary language arts settings, reading instruction is simply taught through phonics and decoding. Little attention is put toward teaching reading comprehension strategies as educators assume it will develop naturally or may in fact be too complex for a young child. However, reading is about deriving meaning from a text and that requires explicit instruction. Students need to be taught how and when to re-read because their comprehension mechanisms have shut down. They need to be instructed on how to interact with a text so that they are engaging in active, meaningful reading. We cannot presume that they will know how to do this and we cannot wait until there are mature readers to introduce these concepts. Students need to develop these strategies as they begin reading so that they do them automatically and acquire an understanding that reading is comprehension. Through my personal attempt to adopt an effective instructional means, I discovered the importance and necessity of making these strategies kinesthetic. The Remote Control Reading and signals made it an interactive process that was tangible and not so abstract. My students not only enjoyed this process, but also grew more excited about reading. The most enriching part of this experience was watching them develop an entirely new perspective on reading. Just as I had shifted my instructional framework, they too followed suit and together we developed a more authentic reading environment that naturally promoted lively discussion and continuous personal interaction. Truly, what more could a grade one teacher ask for? 


\section{References}

Block, C.C., Parris, S.R., \& Cinnamon, S.W. (2008). CPMs: A Kinesthetic Comprehension Strategy. The Reading Teacher, 61(6), 460-470.

Dewitz, P., Jones, J., \& Leahy, S. (2009). Comprehension Strategy Instruction in Core Reading Programs. Reading Research Quarterly, 44(2), 102-126.

Diehl, H. L. (2005). Snapshots of our journey to thoughtful literacy. The Reading Teacher, 59(1), 56-69.

Durkin, D. (1979). What classroom observations reveal about reading comprehension. Reading Research Quarterly, 14, 544-581.

Farr, R. (2008). "Happy thinking along." Retrieved October 27, 2009, from http://www.roger farr.com/

Farr, R., Faszholz, J., Faulds, B., Lewis, M., Lipschutz, J., \& Pinsky, E. (1990). Writing in response to reading. Educational Leadership, 47(6) 66-69.
Gentilucci, J., \& McKeown, R.G. (2007). Thinkaloud strategy: Metacognitive development and monitoring comprehension in the middle school second-language setting. Journal of Adolescent \& Adult Literacy, 51(2), 136-147.

Jamison Rog, L. (2001). Early literacy instruction in kindergarten. Newark, DE: International Reading Association.

Jamison Rog, L. (2007). Marvelous minilessons for teaching beginning writing, K-3. Newark, DE: International Reading Association.

Pinnell, G.S. (2003). What does it mean to comprehend a text. In Teaching for Comprehension in Reading Grades K-2. (pp. 15-32). New York: Scholastic Professional Books.

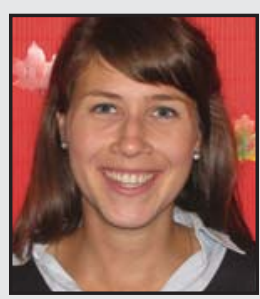

Sarah Kingsley began her teaching career in 2007 after graduating from McGill University. She teaches English Language Arts in grade one at Lower Canada College where she is actively involved in early literacy instruction. Sarah was part of a Critical Friends group in her first year at LCC, which involved meeting with teachers in an informal setting and discussing challenges and successes in education. In 2008 she joined the Action Research group whose focus is on integrating technology into curriculum and practice. 